\title{
AVALIAÇÃO DOS ATRIBUTOS FÍSICOS DO SOLO EM ÁREAS INCLINADAS COM SISTEMA DE PLANTIO DIRETO
}

\author{
Raquel Santana Milagres ${ }^{1}$, Túlio de Almeida Machado², Luciano Baião Vieira ${ }^{3}$, Haroldo Carlos Fernandes ${ }^{3}$ \\ 1Discente da Universidade Federal de Viçosa - Campus Viçosa, Viçosa - MG \\ ${ }^{2}$ Docente do IFGoiano - Campus Morrinhos, Morrinhos - GO \\ ${ }^{3}$ Docente da Universidade Federal de Viçosa - Campus Viçosa, Viçosa - MG \\ *Autor para correspondência: Túlio de Almeida Machado, machado.tulio@gmail.com
}

\begin{abstract}
RESUMO: Em áreas produtoras de grãos com terreno acidentado ou onde o solo é trafegado e trabalhado em condições inadequadas, pode ocorrer mudança nos atributos físicos do solo. 0 objetivo deste estudo foi determinar as mudanças da umidade gravimétrica, densidade aparente, resistência à penetração e teor de matéria seca da cobertura vegetal em áreas de encosta e baixada que sofreram a ação de um escarificador. Foram avaliadas áreas de encosta com e sem escarificação e baixada com escarificação. Para a comparação entre as médias obtidas nos tratamentos, foi realizado um teste de "t" a $5 \%$ de probabilidade. A umidade gravimétrica e a densidade foram avaliadas em três profundidades diferentes. De acordo com a análise estatística utilizada a profundidade afetou apenas valores de umidade gravimétrica no solo. A resistência à penetração não foi modificada nos diferentes tratamentos em função do intervalo de tempo decorrido a partir da escarificação do solo. Os valores de matéria seca, umidade gravimétrica e densidade foram maiores na área de baixada.
\end{abstract}

PALAVRAS-CHAVE: Áreas de encosta, Escarificação, Manejo de solo.

\section{EVALUATION OF PHYSICAL ATTRIBUTES OF THE SOIL IN INCLINED AREAS WITH NO-TILLAGE SYSTEM}

ABSTRACT: In grain producing areas with rough terrain or where the soil is trafficked and worked in inadequate conditions, changes in the soil physical attributes may occur.

The objective of this study was to determine the changes in gravimetric moisture, apparent density, penetration resistance and dry matter content in slope and lowland areas that underwent the action of a scarifier. Sloping areas were evaluated of the vegetal cover with and without scarification and lowered with scarification. For the comparison between the averages obtained in the treatments, a " $\mathrm{t}$ " test at $5 \%$ of probability was performed. Gravimetric moisture and density were evaluated at three different depths. According to the statistical analysis used the depth only affected values for soil moisture. The resistance to penetration was not modified in the different treatments as a function of the time elapsed from the scarification of the soil. The values of dry matter, gravimetric moisture and density were higher in the lowering area.

KEYWORDS: Hillside areas, Scarification, Soil management.

\section{INTRODUÇÃO}

O uso do sistema de plantio direto (SPD) resulta em um ecossistema com grau de perturbação menor que o de outras formas de manejo que utilizam uma intensa mobilização do solo. Desta forma, há um significativo estímulo para a recomposição da biodiversidade do solo, como a do ambiente em si, resultante do menor impacto humano no sistema (Bartz et al., 2014).

0 monitoramento da qualidade do solo por meio de seus atributos físicos é importante para a manutenção e avaliação da sustentabilidade dos sistemas agrícolas. Esse monitoramento pode ser feito por meio de experimentos de longa duração sob sistemas de manejo de solo e de rotação de culturas (Reichert et al., 2003).

Assim, estudar a variabilidade espacial dos atributos físico-hídricos do solo torna-se importante, visto que, em agricultura, informações acerca da estrutura do solo são fundamentais para o entendimento destes atributos e, com base nessas informações, 
pode-se fazer inferências sobre as práticas de manejo do solo e das culturas (Assis e Lanças, 2005), pois a não observância desses conceitos poderá ocasionar erros na amostragem e no manejo do solo.

Normalmente, as determinações de densidade e de porosidade do solo são as avaliações mais comuns e difundidas para identificar camadas compactadas no solo, porém a resistência mecânica deste à penetração, expressada pelo índice de cone, também está diretamente relacionada com o estado de compactação do solo e pode ser uma medida mais sensível para identificar a compactação, especialmente em camadas pouco espessas (Abreu et al., 2004).

Mesmo no SPD é necessário realizar de maneira periódica a mecanização dos solos. Nesse contexto, Vieira \& Klein (2007) relataram que dentre os componentes do manejo, o preparo do solo é o que mais influi em seu comportamento físico, visto que atua diretamente em sua estrutura, causando modificações na porosidade e densidade, que afetam a retenção de água e a resistência mecânica.

Toigo et al. (2015), verificaram que em um nitossolo vermelho cultivado com trigo em sistema de plantio direto, a escarificação mecânica alterou as propriedades físicas do solo na camada superficial, treze meses após a intervenção e o uso do subsolador como forma de reduzir a compactação do solo não contribuiu para 0 aumento da produtividade e qualidade dos grãos de trigo.

Avaliando preparos de solo com grade de discos e escarificador na cultura do mamoeiro, Vitória et al. (2014), verificaram que os coeficientes de variação indicaram baixa variabilidade para a densidade e umidade gravimétrica no solo e alta para macroporosidade e microporosidade nos preparos de solo estudados independente da faixa de profundidade.

Souza et al. (2014), observaram que a subsolagem alterou os atributos do solo, diminuindo densidade do solo e aumentando o volume total de poros, não ocorrendo efeito ao longo do tempo na linha de plantio na cultura do café. Correa et al. (2014) avaliaram que os valores de RP nas áreas cultivadas com cana-de-açúcar foram superiores aos valores observados nas áreas com pastagens e os valores de densidade do solo também foram indicativos de maior degradação dos solos.
Com a introdução do SPD, há aumento na densidade e na resistência à penetração, em comparação com os solos preparados, (Tormena et al, 2004,). Embora esse efeito não tenha limitado o crescimento das raízes e a produção das culturas em solos bem estruturados, a compactação do solo em superfície é apontada como um dos principais problemas do SPD e pode estimular 0 abandono do sistema, mesmo que temporariamente (Rosim et al, 2012).

A partir do exposto, esse trabalho teve 0 objetivo de avaliar e comparar áreas de baixada e encosta cultivadas há 20 anos sob sistema de plantio direto e que foram escarificadas há cinco anos e avaliar se houve mudança em alguns atributos físicos do solo tais como: umidade gravimétrica, densidade, resistência à penetração e índice de matéria seca na superfície do solo.

\section{MATERIAL E MÉTODOS}

O trabalho foi realizado na Fazenda Dom Bosco, próximo às margens da rodovia $B R 356$, no município de Viçosa - MG, com coordenadas $20^{\circ} 45^{\prime} 16,9^{\prime \prime}$ latitude Sul e

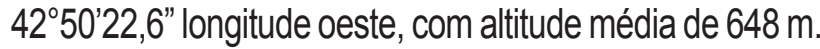
O clima da região é, segundo a classificação de Köppen (1948), do tipo Cwb - clima tropical de altitude com verão chuvoso e temperaturas amenas. 0 regime pluviométrico anual é de $1229 \mathrm{~mm}$ com uma temperatura média anual de 20,6 ${ }^{\circ} \mathrm{C}$ (Embrapa, 2010). 0 solo estudado foi um Latossolo Vermelho-Amarelo. A coleta das amostras para o presente estudo foi realizada no mês de setembro, no período considerado seco para a região.

A área experimental possui 5,5 ha, sendo utilizado um sistema de plantio direto no decorrer do tempo de cultivo de milho. Para a aquisição dos dados, a área total foi delineada em três tratamentos: encosta não escarificada (ENE), encosta com escarificação (ECE) e baixada com escarificação (BCE). As áreas de encosta possuíam declividade média de $12 \%$.

Aárea de ENE não possuía qualquer operação com intuito de movimentação do solo em um período de 20 anos. Já as áreas ECE e BCE, em relação ao preparo de solo, estiveram sujeitas a uma escarificação a uma profundidade de $25 \mathrm{~cm}$ a 5 anos antes da coleta dos dados. A operação de escarificação foi realizada por um conjunto mecanizado formado por um trator da marca Valmet modelo Série Prata com potência nominal no motor de $64,72 \mathrm{~kW}$ que tracionou, utilizando 
seu sistema hidráulico de três pontos um escarificador da marca Inpal modelo CEH de 7 hastes.

Para a condução do estudo, foram determinadas as características físico-hídricas do solo: umidade gravimétrica, densidade, resistência do solo à penetração e massa seca da matéria da cobertura vegetal.

Foi realizado um delineamento inteiramente casualizado, onde em cada área foram coletadas dez repetições com profundidades definidas entre as faixas de 0 a 0,10 m; 0,10 a 0,20 m; e 0,20 a 0,30 $\mathrm{m}$. As amostras coletadas foram acondicionadas em sacos plásticos, lacradas e identificadas até a chegada ao laboratório.

Para a umidade gravimétrica no solo, o método utilizado foi o gravimétrico-padrão, com base no peso de solo seco em estufa na temperatura de 105$110^{\circ} \mathrm{C}$ até atingir massa constante. Já a densidade do solo foi determinada utilizando-se o método do anel volumétrico. Ambas as metodologias foram descritas pela Embrapa (1997).

A resistência do solo à penetração foi realizada em dez pontos distintos de cada tratamento, próximos aos pontos onde foram retiradas simultaneamente as amostras de solo para a determinação da umidade gravimétrica no solo e densidade. A resistência a penetração foi avaliada até $0,30 \mathrm{~m}$ de profundidade com o uso de um penetrômetro digital, DLG, modelo PNT - 2000.

Para a caracterização da cobertura vegetal, foi realizada a coleta de restos culturais na superfície do solo com o auxílio de um gabarito de madeira com 0,25 $\mathrm{m}^{2}(0,5 \times 0,5 \mathrm{~m})$. Foram coletadas aleatoriamente dez amostras para cada área, e acondicionadas em sacos de papel. Posteriormente secas em estufa a $65^{\circ} \mathrm{C}$ por 72 horas ou até atingirem peso constante, conforme metodologia descrita por Chaila (1986). O valor de matéria seca é obtido dividindo o peso da cobertura vegetal após a secagem, pelo valor da área do gabarito, e expresso em $\mathrm{kg} \mathrm{ha}^{-1}$

Para as variáveis de umidade gravimétrica e densidade, houve a comparação entre Enconsta não escarificada (ENE) x Econsta com escarificação (ECE), para áreas de encosta e ECE x Baixada com escarificação (BCE) para áreas que sofreram a ação da escarificação. Foram também comparadas variáveis de umidade gravimétrica e densidade do solo nas diferentes profundidades em cada tratamento. A resistência a penetração e o teor de matéria seca foram comparados entre os tratamentos.

Os valores passaram por um análise de variância ao teste $\mathrm{F}$ a $5 \%$ de probabilidade e, posteriormente, foram realizas comparações pelo teste "t" de Student para amostras independentes e variâncias homogêneas. Foram consideradas diferenças significativas a $5 \%$. As análises foram realizadas pelo software estatístico Assistat, versão 7.6 Beta.

\section{RESULTADOS E DISCUSSÃO}

Os resultados obtidos de umidade gravimétrica e da densidade do solo nos diferentes níveis de profundidade são mostrados na Tabela 1, em que, foram comparados em duas diferentes situações, ENE $x$ ECE e ECE x BCE.

Tabela 1. Valores de umidade gravimétrica e da densidade do solo nos diferentes níveis de profundidade

\begin{tabular}{cccc}
\hline \multirow{2}{*}{ Tratamentos } & \multicolumn{3}{c}{ Umidade gravimétrica $(\%)$} \\
\cline { 2 - 4 } & $0-10$ & $10-20$ & $20-30$ \\
\hline ENE & $20,79 \mathrm{a}$ & $22,03 \mathrm{a}$ & $24,62 \mathrm{a}$ \\
$\mathrm{X}$ & $17,62 \mathrm{a}$ & $21,16 \mathrm{a}$ & $25,56 \mathrm{a}$ \\
ECE & $17,62 \mathrm{~b}$ & $21,16 \mathrm{~b}$ & $25,56 \mathrm{a}$ \\
ECE & $25,91 \mathrm{a}$ & $26,71 \mathrm{a}$ & $29,30 \mathrm{a}$ \\
X & & Densidade $\left(\mathrm{g} \mathrm{cm}^{-3}\right)$ & $20-30$ \\
BCE & $0-10$ & $10-20$ & $2,89 \mathrm{a}$ \\
& $2,79 \mathrm{~b}$ & $2,92 \mathrm{a}$ & $2,89 \mathrm{a}$ \\
\hline ENE & $2,99 \mathrm{a}$ & $2,95 \mathrm{a}$ & $2,84 \mathrm{a}$ \\
XCE & $2,99 \mathrm{a}$ & $2,95 \mathrm{a}$ & $2,58 \mathrm{~b}$ \\
ECE & $2,42 \mathrm{~b}$ & $2,61 \mathrm{~b}$ & \\
X & & &
\end{tabular}

As médias seguidas pela mesma letra, na coluna, não diferem estatisticamente entre si, pelo teste " $\mathrm{t}$ " a $5 \%$ de probabilidade. ENE: encosta não escarificada; ECE: encosta com escarificação e BCE: baixada com escarificação. 
Para a umidade gravimétrica no cenário ENE $x$ ECE não houve variação significativa das médias observadas nos diferentes níveis de profundidade. Avaliando o tempo de duração escarificação mecânica, Drescher et al. (2016) avaliaram um sistema plantio direto e observaram uma menor resistência do solo a penetração em até 18 meses após a passagem do implemento.

No presente estudo, o comportamento do solo se deu pelo fato de que a escarificação sofrida em parte da encosta foi realizada há cinco anos antes da coleta das amostras, podendo assim, nesse período, haver uma reestruturação do solo em toda a sua estrutura de retenção de água. Porém, o efeito dessa prática, em solo sob "plantio direto", tem sido avaliado como efêmero, persistindo por aproximadamente um ano (Nicoloso et al., 2008; Girardello et al., 2011; Silva et al., 2012),

Para a condição de comparação entre áreas escarificadas, houve diferença da umidade gravimétrica na camada do solo de $0-20 \mathrm{~cm}$ de profundidade, onde maiores valores foram encontrados para a condição $B C E$. Esse fato se deve a uma maior cobertura vegetal sobre a área de BCE e também por ser uma área plana, o que favorece a uma maior umidade.

Corroborando com os resultados, Luciano et al. (2010), avaliando uma área de SPD por cinco anos consecutivos concluíram que a adoção do plantio direto fez com que as raízes das culturas adicionaram maior quantidade de matéria orgânica ao solo nesta camada do que nas demais, influenciando o carbono orgânico e a agregação e, principalmente, a abertura de galerias após a sua decomposição.

Em ENE x ECE não houve variação significativa da densidade de 10 a $20 \mathrm{~cm}$. Apenas na faixa superficial do solo $(0-10 \mathrm{~cm})$ se obteve variação desse parâmetro, onde, o tratamento ECE apresentou maiores valores em função do preparo de solo sofrido na camada superficial. Esse comportamento deve-se a exposição da camada superficial às intempéries após a escarificação, onde esta pode ter sofrido uma maior influência de escoamentos e, por seguinte, transporte de sedimentos. Essa tendência também é embasada pela influência da densidade na umidade gravimétrica no solo, em que, para menores valores de umidade, foram encontradas as maiores densidades.

Nas áreas escarificadas (ECE x BCE), houve diferença estatística de valores de densidade do solo em relação a todas as profundidades analisadas, em que, menores valores foram encontrados para a condição BCE. Esse comportamento, assim como para valores de umidade gravimétrica, pode ser explicado por meio da maior quantidade de cobertura vegetal nessa área.

Dentro desse contexto, Viana et al. (2011), avaliaram que a matéria orgânica do solo influencia direta e indiretamente todas as características do solo, de modo que a redução do carbono orgânico total está relacionada à degradação física dos solos, e seu incremento através do manejo adequado modifica a capacidade de carga dos solos, que se tornam menos vulneráveis à compactação, que está intimamente ligada à densidade do solo.

Santos et al. (2012), verificaram a variabilidade espacial da densidade e umidade de um Latossolo Vermelho distroférrico típico após o cultivo de soja, concluíram que os sistemas de preparo que revolvem menos o solo e acumulam resíduos culturais na superfície preservam sua estrutura e retêm mais água na camada superficial, principalmente pelo aumento do conteúdo de matéria orgânica, que atua como agente "cimentante" dos agregados do solo e da microporosidade.

Os valores de umidade gravimétrica $e$ densidade do solo nas diferentes profundidades dos tratamentos avaliados são apresentados na Tabela 2.

Tabela 2. Valores de umidade gravimétrica e densidade em diferentes níveis de profundidade para os diferentes tratamentos(1).

\begin{tabular}{cccc}
\hline \multirow{2}{*}{ Profundidade $(\mathrm{cm})$} & ENE & ECE & BCE \\
\cline { 2 - 4 } & & Umidade gravimétrica $(\%)$ & $25,91 \mathrm{a}$ \\
\hline $0-10$ & $20,79 \mathrm{~b}$ & $17,62 \mathrm{c}$ & $26,71 \mathrm{a}$ \\
$10-20$ & $22,03 \mathrm{ab}$ & $21,16 \mathrm{~b}$ & $29,30 \mathrm{a}$ \\
$20-30$ & $24,62 \mathrm{a}$ & $25,56 \mathrm{a}$ & \\
& & Densidade $\left(\mathrm{g} \mathrm{cm}^{-3}\right)$ & $2,42 \mathrm{a}$ \\
$0-10$ & $2,79 \mathrm{a}$ & $2,99 \mathrm{a}$ & $2,61 \mathrm{a}$ \\
$10-20$ & $2,92 \mathrm{a}$ & $2,95 \mathrm{a}$ & $2,58 \mathrm{a}$ \\
$20-30$ & $2,89 \mathrm{a}$ & $2,84 \mathrm{a}$ & \\
\hline
\end{tabular}

As médias seguidas pela mesma letra, na coluna, não diferem estatisticamente entre si, pelo teste " $\mathrm{t}$ " a $5 \%$ de probabilidade. ENE: encosta não escarificada; ECE: encosta com escarificação e BCE: baixada com escarificação. 
A umidade gravimétrica em ENE (máxima de $32,87 \%$ e mínima de $18,24 \%$ ) e ECE (máxima de $31,87 \%$ e mínima de $22,41 \%$ ) apresentou maiores valores nas maiores profundidades, onde as camadas superficiais se diferiram estatisticamente das camadas mais profundas. No tratamento $\mathrm{BCE}$, todos os valores foram estatisticamente iguais no que diz respeito a essa característica. Esse comportamento se deve principalmente a uma quantidade menor de matéria seca e uma maior inclinação do terreno, onde há uma menor cobertura vegetal e facilidade de escoamento em ENE e ECE. O processo inverso acontece no tratamento $\mathrm{BCE}$, onde, com uma maior cobertura vegetal aliada a escarificação, principalmente na camada de $0-20 \mathrm{~cm}$, provavelmente proporcionou uma maior retenção da umidade gravimétrica nesses níveis de profundidade.

Os valores de densidade nos diferentes níveis de profundidade foram estatisticamente semelhantes em todos os tratamentos avaliados, apresentando que, para condições de encosta, a densidade não se diferenciou mesmo com diferentes valores de umidade gravimétrica. Esse comportamento sugere que, mesmo nas áreas que sofreram a escarificação, houve uma reestruturação do solo nas camadas analisadas.

0 presente estudo corrobora com Torres et al. (2015), que avaliaram as alterações ocorridas nos atributos físicos do solo após o preparo mínimo utilizando a enxada rotativa e arado escarificador verificaram que em um mesmo ano avaliado a densidade do solo no processo de escarificação foi estatisticamente semelhante em camadas até $40 \mathrm{~cm}$ de profundidade.

Os valores de resistência à penetração a $30 \mathrm{~cm}$ e a quantidade de matéria seca na superfície do solo nos diferentes tratamentos avaliados são mostrados na Tabela 3.

Tabela 3. Valores de resistência à penetração e teor de matéria seca nos diferentes tratamentos.

\begin{tabular}{ccc}
\hline Tratamentos & Resistência à penetração $(\mathrm{MPa})$ & Teor de matéria seca $\left(\mathrm{kg} \mathrm{ha}^{-1}\right)$ \\
\hline ENE & $6,08 \mathrm{a}$ & $4,30 \mathrm{~b}$ \\
ECE & $5,86 \mathrm{a}$ & $7,27 \mathrm{ab}$ \\
BCE & $5,82 \mathrm{a}$ & $10,56 \mathrm{a}$ \\
\hline
\end{tabular}

As médias seguidas pela mesma letra, na coluna, não diferem estatisticamente entre si, pelo teste "t" a $5 \%$ de probabilidade. ENE: encosta não escarificada; ECE: encosta com escarificação e BCE: baixada com escarificação.

Os valores de resistência à penetração não foram diferentes entre si, com valor médio considerando todos os tratamentos em torno de 5,92 $\mathrm{MPa}$. Estes valores são semelhantes em função do processo de preparo do solo com escarificador ter sido realizado à 5 anos antes da coleta dos dados, mostrando que com 0 passar do tempo e em função do tráfego de máquinas e a compactação natural do solo, houve a presença de maiores valores de densidade e resistência do solo à penetração em sistemas de preparo com menor mobilização do solo.

Neste sentido, os elevados valores de resistência à penetração que foram verificados são indicativos de manejo realizado inadequadamente. Nesse estudo, tais resultados denotam alterações nas condições físicas dos solos, o que acarreta no favorecimento dos processos de encharcamento, na redução da infiltração e no aumento do escoamento superficial e consequentemente no aumento dos processos erosivos.
Os valores de teor de matéria seca foram maiores, e estatisticamente semelhantes, nas áreas que sofreram escarificação. Mesmo os valores de resistência à penetração sendo próximos, houve diferença na matéria seca na superfície do solo, com menores valores de densidade e maiores valores do teor de água houve um maior desenvolvimento de raízes, e, consequentemente um maior valor de matéria seca.

Os valores para o teor de matéria orgânica seca em BCE e ECE foram estatisticamente semelhantes. Esse comportamento pode ser evidenciado pela ação da escarificação que além de descompactar o solo na ocasião em que foi realizada quebrou a dormência do banco de sementes dormentes no solo ou que estavam na superfície, fazendo com que novas plantas se desenvolvessem e posteriormente viessem a ser parte da cobertura vegetal.

Para resolver o problema causado pela compactação da camada superficial do solo, muitos 
agricultores retornam aos métodos de preparo tradicionais, com revolvimento parcial ou total do solo. Segundo Coelho Filho et al. (2001), em razão dos atributos do solo e, em especial de a densidade não ser homogênea e apresentar dependência espacial, a variabilidade causa problemas em experimentação de campo, especialmente no manejo da irrigação.

Diante do presente estudo, pôde-se verificar que os valores da umidade gravimétrica para BCE foram maiores quando comparados aos outros tratamentos e densidade do solo para as áreas de encosta foram maiores quando comparados com as áreas de baixada.

Os valores da umidade gravimétrica foram maiores com 0 aumento da profundidade nos tratamentos avaliados, onde, as partes de encosta foram mais afetadas por esse comportamento.

0 tratamento de baixada se manteve com valores semelhantes em função de uma maior cobertura do solo. A resistência à penetração foi semelhante para todos os tratamentos, mostrando que o tráfego de máquinas afetou diretamente esse atributo do solo. 0 teor de matéria seca seguiu tendência de obter maiores valores em áreas com menores densidades e maior concentração do teor de água.

\section{REFERÊNCIAS BIBLIOGRÁFICAS}

Abreu, S.L.; Reichert, J.M.; Reinert, D.J. Escarificação mecânica e biológica para a redução da compactação em argissolo franco-arenoso sob plantio direto. Revista Brasileira de Ciências do Solo, 2004, 28, 3, 519-531.

Assis, R.L.; Lanças, K.P. Avaliação dos atributos físicos de um Nitossolo Vermelho Distroférrico sob sistema plantio direto, preparo convencional e mata nativa. Revista Brasileira de Ciência do Solo, 2005, 29, 4, 515-522.

Bartz, M.L.C,; Brown, G.G,; Rosa, M.G,; Klauberg-Filho, O,; James S.W,; Decaëns, T.; Baretta, D. Earthworm richness in land-use systems in Santa Catarina, Brazil. Applied Soil Ecology, 2014, 83, 59-70.

Coelho Filho, M.A.; Coelho, R.D.; Gonçalves, A.C.A. Variabilidade espacial de variáveis físico-hídrícas do solo em um pomar de lima ácida Tahiti, irrigada por microaspersão. Revista Brasileira de Engenharia Agrícola e Ambiental, 2001, 6, 2, 239-246.
Correa, E.A; Moraes, I.C.; Guedes Júnior, E.; Couto Júnior, A.; Pinto, S.A.F.P. Resistência à penetração e densidade do solo como indicadores na análise da susceptibilidade a erosão hídrica dos solos. Revista Geonorte, 2014, 10, 1, 141-146.

Drescher, M.S.; Reinert, D.J.; Denardin, J.E.; Gubiani, P.I.; Faganello, A.; Drescher, G.L. Duração das alterações em propriedades físico-hídricas de Latossolo argiloso decorrentes da escarificação mecânica. Pesquisa Agropecuária Brasileira, 2016, 51, 2, 159-168.

Embrapa - Empresa Brasileira de Pesquisa Agropecuária. Centro Nacional de Pesquisa de Solos. Manual e métodos de análise do solo. 2.ed. Rio de Janeiro: Embrapa 1997. 212.

Embrapa - Empresa Brasileira de Pesquisa Agropecuária. Índices pluviométricos em Minas Gerais. Embrapa Milho e Sorgo - Sete Lagoas, 2010. 88.

Girardello, V.C.; Amado, T.J.C.; Nicoloso, R.S.; Horbe, T.A.N.; Ferreira, A.O.; Tabaldi, F.M.; Lanzanova, M.E. Alterações nos atributos físicos de um Latossolo Vermelho sob plantio direto induzidas por diferentes tipos de escarificadores e o rendimento da soja. Revista Brasileira de Ciências do Solo, 2011, 35, 2115-2126.

Koppen, W. Climatologia com un estudio de los climas de la tierra. México: Fondo de Cultura Econômica, 1948. 478 .

Luciano, R.V.; Bertol, I.; Barbosa, F.T.; Kurtz, C.; Fayad, J.A. Propriedades físicas e carbono orgânico do solo sob plantio direto comparados à mata natural, num Cambissolo Háplico. Revista de Ciências Agroveterinárias, 2010, 9, 1, 09-19.

Nicoloso, R.S.; Amado, T.J.C.; Schneider, S.; Lanzanova, M.E.; Girardello, V.C. Bragagnolo, J. Eficiência da escarificação mecânica e biológica na melhoria dos atributos físicos de um Latossolo muito argiloso e no incremento do rendimento de soja. Revista Brasileira de Ciências do Solo, 2008, 32, 1723-1734.

Reichert, J.M.; Reinert, D.J.; Braida, J.A. Qualidade dos solos e sustentabilidade de sistemas agrícolas. Revista Ciência \& Ambiente, 2003, 27, 1, 29-48. 
Rosim, D.C.; De Maria, I.C.; Silval, R.L.; Silva, A.P. Compactação de um Latossolo Vermelho Distroférrico com diferentes quantidades e manejos de palha em superfície. Revista Bragantia, 2012, 71, 2, 502-508.

Santos, D.; Souza, E.G.; Nobrega, L.H.P.; Bazzi, C.L.; Gonçalves Júnior, A.C. Variabilidade espacial de atributos físicos de um Latossolo Vermelho após cultivo de soja. Revista Brasileira de Engenharia Agrícola e Ambiental, 2012, 16, 8, 843-848.

Silva, S.G.C.; Silva, A.P.; Giarola, N.F.B.; Tormena, C.A.; SÁ, J.C.M. Temporary effect of chiseling on the compaction of a Rhodic Hapludox under no-tillage. Revista Brasileira de Ciências do Solo, 2012, 36, 547555.

Souza, M.S.; Bonomo, R.; Pires, F.R.; Bonomo, D.Z. Atributos físicos do solo em lavoura de cafeeiro Conilon submetida à subsolagem. Engenharia na Agricultura, 2014, 22, 5, 413-425.

Toigo, S.; Braida, J.A.; Possenti, J.C.; Brandelero, E.M.; Baesso, M.M. Atributos físicos de um nitossolo vermelho cultivado com trigo, em sistema de plantio direto, submetido à compactação e escarificação. Engenharia na agricultura, 2015, 23, 1, 19-28.
Torres, L.R.T.; Angelotti Netto, A.; Souza, Z.M.; Assis, L.R. Alterações causadas nos atributos físicos após preparo do solo com arado escarificador e enxada rotativa. Magistra, 2015, 27, 3, 315-325.

Tormena, C.A.; Vidigal Filho, P.S.; Gonçalves, A.C.A.; Araújo, M.A.; Pinto, J.C. Influência de diferentes sistemas de preparo do solo nas propriedades físicas de um Latossolo Vermelho distrófico. Revista Brasileira de Engenharia Agrícola e Ambiental, 2004, 8, 1, 65-71.

Viana, E.T.; Batista, M.A.; Tormena, C.A.; Costa, A.C.S.; Inoue, T.T. Atributos físicos e carbono orgânico em Latossolo Vermelho sob diferentes sistemas de uso e manejo. Revista Brasileira de Ciência do Solo, 2011, $35,6,2105-2114$.

Vieira, M.L.; Klein, V.A. Propriedades físicohídricas de um Latossolo vermelho submetido a diferentes sistemas de manejo. Revista Brasileira de Ciência do Solo, 2007, 31, 6, 1271-1280.

Vitória, E.L.; Calvi, D.P.; Barbosa, M.A.; Canal, L. Variabilidade espacial dos atributos físicos em áreas cultivadas com mamão sob diferentes preparos de solo. Engenharia na agricultura, 2014, 22, 2, 150-161. 